\title{
Construction System for Single-Family Homes using Load Bearing Straw Bale Walls Quivillungo Community, Bolivar, Ecuador
}

\author{
${ }^{1,2}$ Paulina Viera, ${ }^{2}$ Jose Pachala, ${ }^{2}$ Hernan Rosero, ${ }^{1}$ Jose Maria Monzo and ${ }^{3}$ Pablo Caiza \\ ${ }^{1}$ Concrete Science and Technology University Institute, Universitat Politecnica de Valencia, \\ Valencia, Espana \\ ${ }^{2}$ Department of Physical Sciences and Mathematics, Faculty of Engineering, \\ Universidad Central del Ecuador, Quito, Ecuador \\ ${ }^{3}$ Department of Earth and Construction Sciences, Universidad de las Fuerzas Armadas ESPE, \\ Sangolqui, Ecuador
}

\begin{abstract}
This study begins by describing how our team chose an area in the Ecuadorian Andean Region where a prototype single-family home using load bearing straw-bale-walls could be successfully built. The criteria used in this search were based on results from geographic information systems. The next section describes the design and manufacture of a baler machine which is essential to the feasibility of the strawbale home construction procedure. The study then goes on to explain the features of the most important elements of the single-family home structure: foundations, straw walls, wall crowns, roof and structural plaster. The prototype home was built in accordance with existing standards from other countries, taking into account the high seismic hazard of the geographic region and applying the specific capacities of the Quivillungo community. The construction was validated using analytic models that show the existence of relatively low stresses and deformations and highlight the structural importance of the plaster.
\end{abstract}

Key words: Ecuadorian Andean Region, straw bearing walls, baler machine, structural plaster, prototype, strawbale home

\section{INTRODUCTION}

In rural Ecuador, over 200,000 households live in overcrowded conditions. Further, to this issue in two provinces that, we will look at in more detail in this study, Bolivar and Chimborazo there is a deficit of approximately 127,097 houses (Anonymous, 2005). The national Government has set a goal to eliminate the qualitative and quantitative housing deficit by the year 2025. To do, so, it will have to invest close to US $\$ 5.5$ billon, approximately US \$ 340 million annually, over the next 15 years (Anonymous, 2005, 2018).

We propose that strawbale construction is an eco-friendly construction system in terms of production, placement, functioning, operation and maintenance as well as in events requiring reconstruction (Bhattarai et al., 2012).

This study describes a project to build a single family home with load bearing strawbale walls in the Andean Region of Ecuador an area with high seismic hazard.

Our team began by seeking out a geographic area where the prototype could be successfully built. The selection criteria related to the ease of finding the straw needed to build the home, proximity to access roads and being located on relatively flat terrain. The predisposition of local communities in getting involved in this project proved to be a key issue. We complemented data from the National Autonomous Institute of Agricultural Research (INIAP) and the Ministry of Agriculture, Livestock, Aquaculture and Fisheries (MAGAP) (2016), using Geographic Information Systems (GIS). As a result we chose a site that would be ideal for implementing the project: the Quivillungo community in Gabriel Ignacio de Veintimilla Parish District, Guaranda Canton, Bolivar Province.

The team proceeded to build a single-family home using construction techniques originating in other countries but modified to adapt to the actual seismic hazard and construction conditions of this specific project. We took care in documenting the construction process which is especially important because despite the fact that strawbale construction has been applied in North America, since, the beginning of the 20th century and began being used around the world in the 90's (Minke and Mahlke, 2006) it has never been employed in Ecuador (Pachala Curi and Rosero Munoz, 2016).

Corresponding Author: Paulina Viera, Concrete Science and Technology University Institute, Universitat Politecnica de Valencia, Valencia, Espana 
Launching this process required starting from scratch; the team had to design and build even the most basic tool which in this case is a baler machine. The actual construction process for this type of single-family home was also a new experience for our team but afforded us the opportunity to try out new alternatives with the support of the Quivillungo community's ability and ingenuity.

This project included technical documents such as architectural plans and structural models which were optimized and validated based on the actually observed structural behavior of the prototype.

\section{MATERIALS AND METHODS}

Theoretical framework: Strawbale walls can support vertical loads of more than $500 \mathrm{~kg}$ per linear meter (Minke and Mahlke, 2006; Romans, 2014). It has also been observed that the thickness of the plaster coating has a large influence on the strength of the bale and that the crowning element (perimeter ring beam) allows for uniform and centered distribution of the loads (Araneda and Munoz, 2010).

In addition, strawbale walls respond well to earthquakes due to their ductility and their capacity for elastic deformation, allowing them to dissipate the kinetic energy resulting from the earthquake (King et al., 2006; Araneda and Munoz, 2010; Nitzkin, 2013). The seismic vulnerability of buildings having load-bearing straw-bale walls can also be reduced by using stress or sandwich panels which act in a way similar to a rigid and strong skin on each side of a soft and insulating core. The relative rigidity of the coatings attracts the entire load while the strawbales at the core serve as insulation a shear transfer medium and reinforcement of the plaster coatings. However, unlike other types of stress skin systems, the walls of well-stacked bales form a core with reserve resistance to support failed coatings and also have the ability to absorb energy (mainly from the seismic loads but not limited thereto) as well as deform elastically and inelastically without collapsing (King, 2006).

Today, residential and public buildings including schools, warehouses, theaters and offices that use straw walls are constructed applying recognized technical principles. For example, in Spain, from 2006-2016, more than a hundred buildings have been constructed applying the Straw Walls Technical Building Code. (Nowak and Kolaczkowski, 2015; Cebada Sanchez, 2017).

The growing numbers of strawbale constructions around the world clearly show the feasibility of this
Table 1: Surface area, production and sales of wheat (dry grain), by province

\begin{tabular}{lccc}
\hline & \multicolumn{2}{c}{ Surface area (Has.) } & \\
Mountain region & --- & Harvested & $\begin{array}{c}\text { Production } \\
\text { (Tm) }\end{array}$ \\
provinces & Sown & 321 & 141 \\
Azuay & 338 & 955 & 1087 \\
Bolivar & 1015 & 26 & 45 \\
Canar & 33 & 76 & 169 \\
Carchi & 76 & 217 & 51 \\
Cotopaxi & 217 & 1608 & 2804 \\
Chimborazo & 1687 & 409 & 738 \\
Imbabura & 441 & 108 & 110 \\
Loja & 108 & 685 & 1595 \\
Pichincha & 685 & 17 & 6 \\
Tungurahua & 17 & &
\end{tabular}

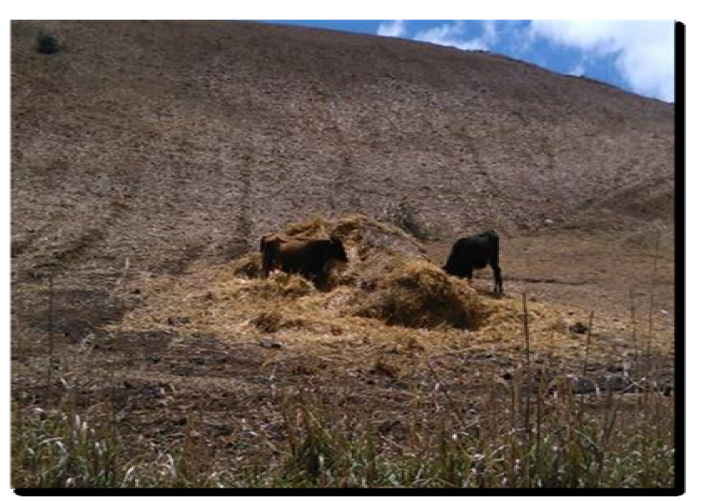

Fig. 1: Raw material: wheat straw in the Andean area of Ecuador; Thesis (Pachala Curi and Rosero Munoz, 2016)

construction method as do strawbale houses dating back more than 100 years but still found in perfect conditions. The broad range of examples of such experiences provide a solid basis for confidence on the use of the strawbale as construction material (Romans, 2014).

\section{Deciding on the best areas to implement the project}

Raw material for the strawbales: Figure 1 shows wheat is one of the most important products in the Ecuadorian diet. Its consumption has increased notably as a result of rapid population growth $(1.2 \%$ per year), changes in consumption habits and relatively low prices of wheat grain products.

Table 1 shows data on the surface area and volume of wheat production Ecuador, detailed by province. We can clearly observe the importance of this product in Bolivar and Chimborazo Provinces.

Average volume of wheat production per square $100 \mathrm{~m}$ (ha) in Ecuador is generally, low (0.6 Tm/ha). This is mainly due to the lack of technology used in production processes as well as the large number of smallholder producers that harvest this crop. In fact, studies show that $37.84 \%$ of wheat producers 

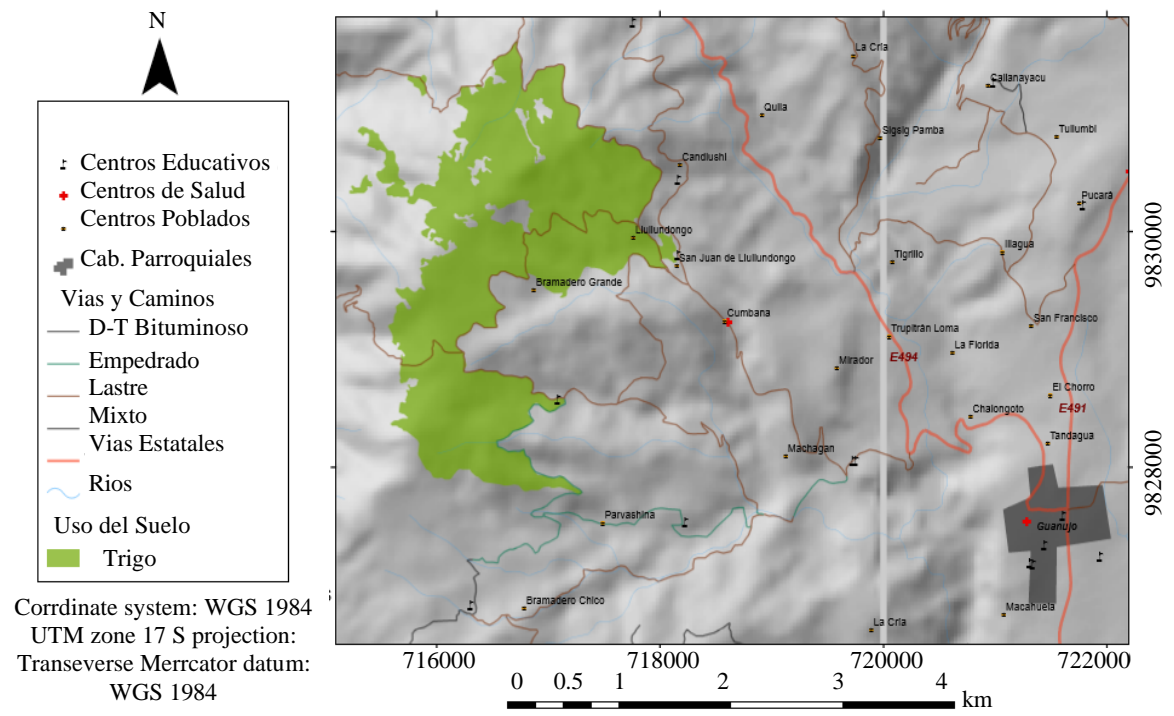

Fig. 2: Grain crops in Bolivar Province
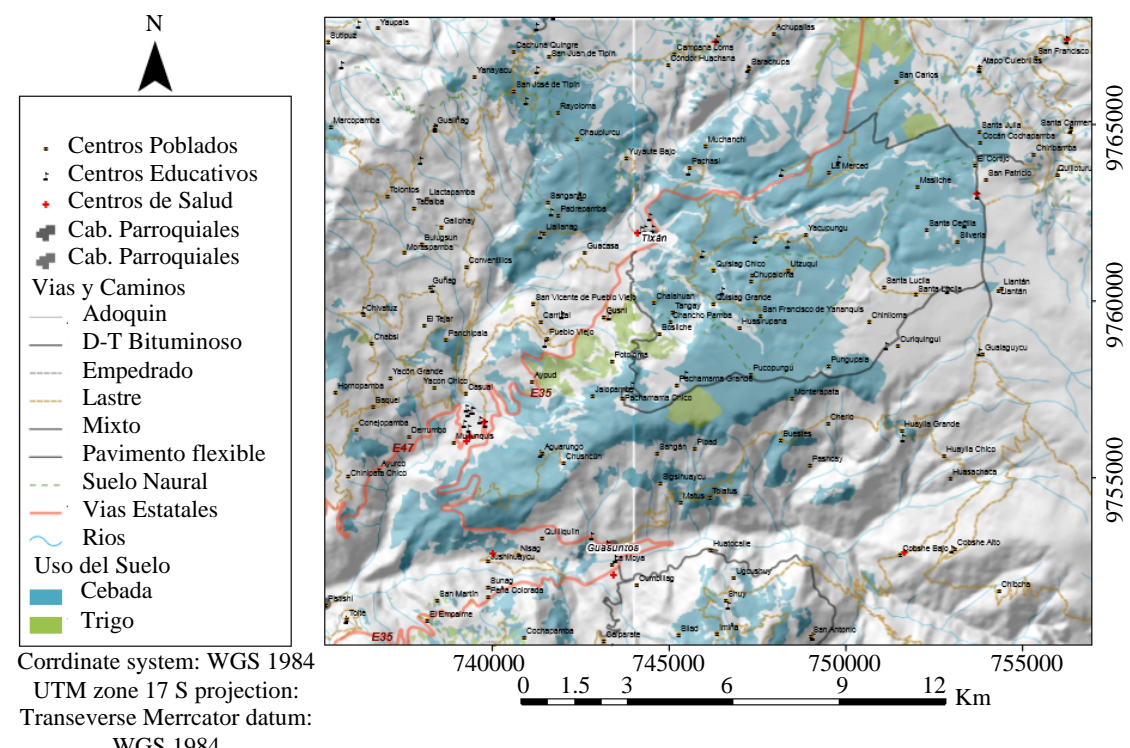
WGS 1984

Fig. 3: Grain crops in Chimborazo Province

use traditional farming systems while $53.74 \%$ use semi-technical systems. Only, $8.1 \%$ use technical farming systems. Wheat production is used for making bread, noodles, crackers and cookies and animal feed. However, wheat straw (Fig. 1) is not put to any technical use and usually is burned.

Maps of grain production areas in Ecuador: For typical examples, (Fig. 2 and 3) which are maps of wheat and barley crop areas in Bolivar and Chimborazo Provinces. These areas are shown in brighter colors.
Figure 2 shows relatively major grain production areas that are located close to the state highway system on medium slopes at high altitudes.

Figure 3 shows larger areas. Similar to Fig. 2 these are located close to highways have medium slopes and high altitude. Comparing the two zones, Chimborazo Province has the advantage of larger crop areas and therefore, an abundance of straw. However, the community's predisposition to participate in the project ended up being the determining factor in deciding where it would be carried out. Quivillungo in Bolivar Province was chosen for this reason. 


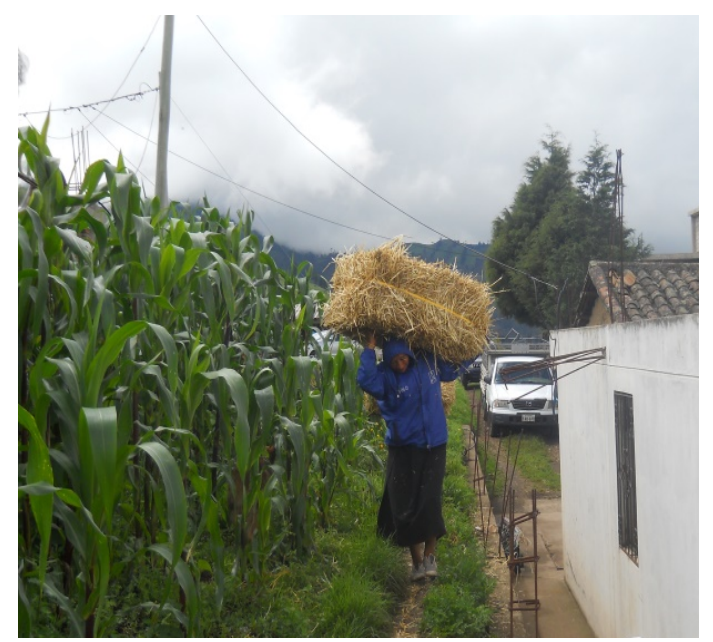

Fig. 4: Strawbales

Strawbale characteristics: To be able to use wheat straw in bales for housing construction an artisanal baler machine had to be designed and built. This design was based on strawbale specifications and dimensions defined by Minke and Mahlke (2006). These dimensions are: length $=80 \pm 2 \mathrm{~cm}$, width $=50 \pm 2 \mathrm{~cm}$, height $=35 \pm 2 \mathrm{~cm}$ (Fig. 4). Additionally, wall overlaps require strawbales with the following dimensions: length $=50 \pm 2 \mathrm{~cm}$, width $=50 \pm 2 \mathrm{~cm}$, height $=35 \pm 2 \mathrm{~cm}$.

In addition to producing bales with the abovementioned dimensions, the baler machine needs to compress the straw to densities of at least $80 \mathrm{~kg} / \mathrm{m}^{3}$. To achieve this we used 25 ton capacity hydraulic jack. The baler's A36 steel plates are $6 \mathrm{~mm}$ thick. Figure 5 shows the front and sides of this machine.

Figure 6, shows a photograph of the built machine. When operated, the front cover closes and an initial amount of straw is introduced through the top where there is also a cover. With the help of the hydraulic jack, the straw is compressed. The jack piston is lowered, more straw is added and the process is repeated until achieving the final bale dimensions.

It is important to point out the relatively low cost involved in building this machine. Details on the cost in US dollars is shown in Table 2 .

Architectural design: The architectural proposal for a single-family home with straw bearing walls has the minimum dimensions specified in Chapter 4: standards by type of building, first section: home buildings, taken from ordinance 3457 of the Quito Metropolitan Council Architectural and Urban Planning Standards. The floor plan dimensions are $7 \times 7 \mathrm{~m}$. Figure 7-10 show the floor plan and architectural side views. (a)

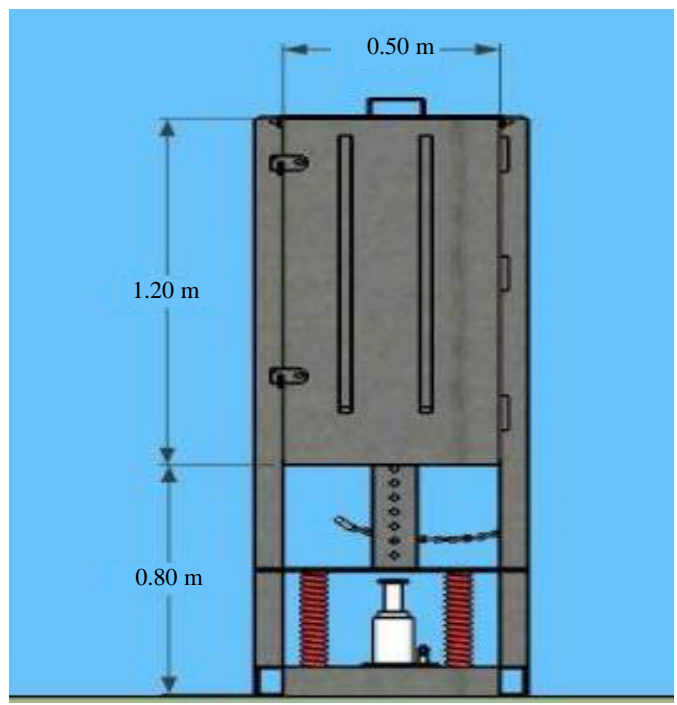

(b)

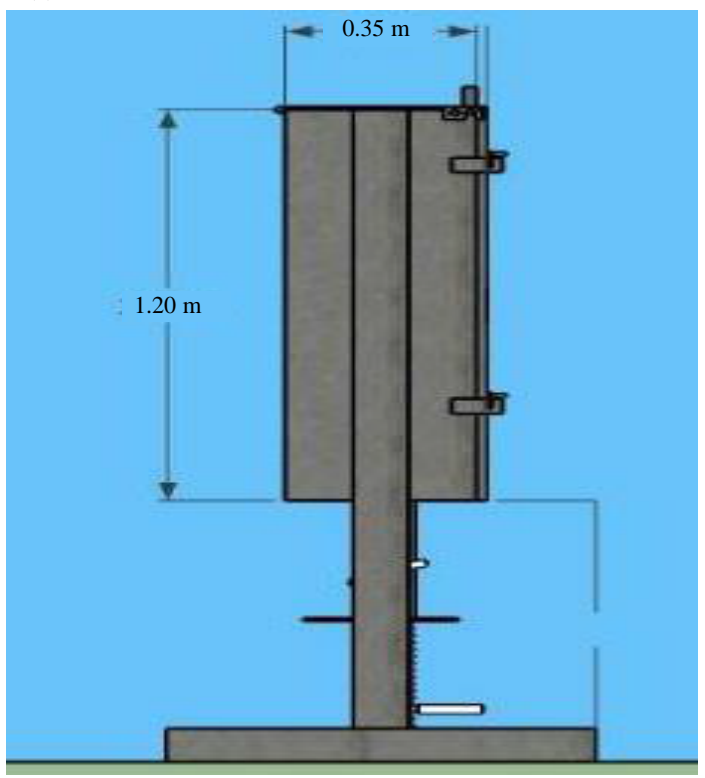

Fig. 5: a, b) Front and side views of the baler machine

Table 2: Budget to build the baler machine (Pachala Curi and Rosero Munoz, 2016)

\begin{tabular}{|c|c|c|c|c|}
\hline Description of the material & Units & No. & Unit values & Total values \\
\hline $\begin{array}{l}\text { Unc oated steel plate, } \\
1220 \times 2440 \mathrm{~mm} \mathrm{e}=6 \mathrm{~mm}\end{array}$ & 1 & 1 & 88.24 & 88.24 \\
\hline $\begin{array}{l}\text { Sqaure tube } 60 \times 60 \mathrm{~mm} \\
\mathrm{e}=3 \mathrm{~mm}\end{array}$ & 1 & 1 & 48.00 & 48.00 \\
\hline $\begin{array}{l}\text { Sqaure tube } 50 \times 50 \mathrm{~mm} \\
\mathrm{e}=3 \mathrm{~mm}\end{array}$ & 1 & 1 & 29.93 & 29.93 \\
\hline $\begin{array}{l}\text { Rectanglular tube } 50 \times 100 \mathrm{~mm} \\
\mathrm{e}=4 \mathrm{~mm}\end{array}$ & 1 & 1 & 61.00 & 61.00 \\
\hline Hinge & 1 & 4 & 01.90 & 07.60 \\
\hline Spring & 1 & 2 & 20.00 & 40.00 \\
\hline Paint and labor & Gallon & 1 & 50.00 & 50.00 \\
\hline 25-ton hy draulic jack & 1 & 1 & 82.35 & 82.35 \\
\hline $\begin{array}{l}\text { Labor to build the machine } \\
\text { Total }\end{array}$ & 1 & 1 & 250.00 & $\begin{array}{l}250.00 \\
657.12\end{array}$ \\
\hline Total & & & & \\
\hline
\end{tabular}




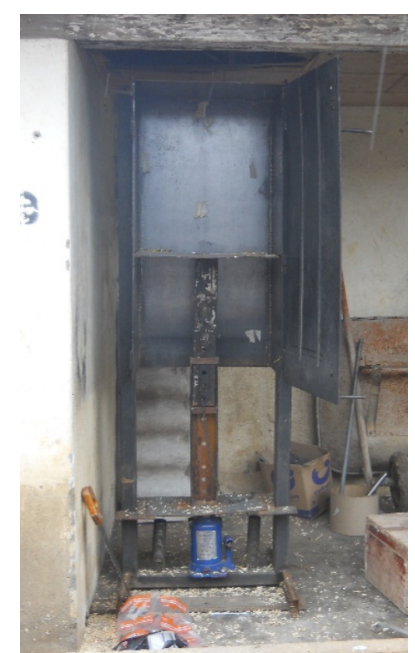

Fig. 6: Baler machine used in the project

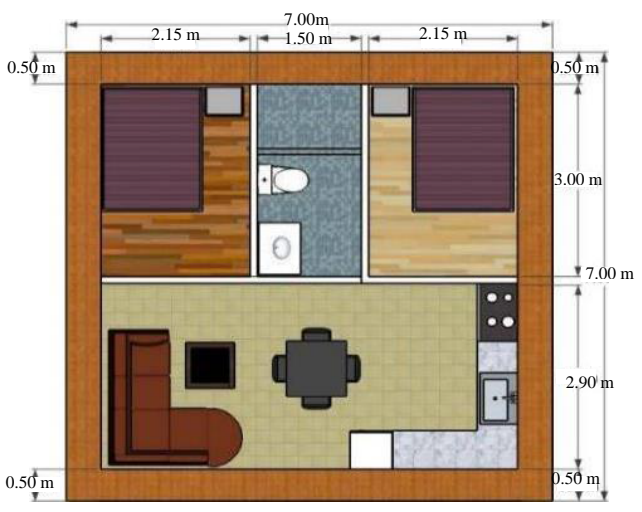

Fig. 7: Architectural floor plan of the single family home

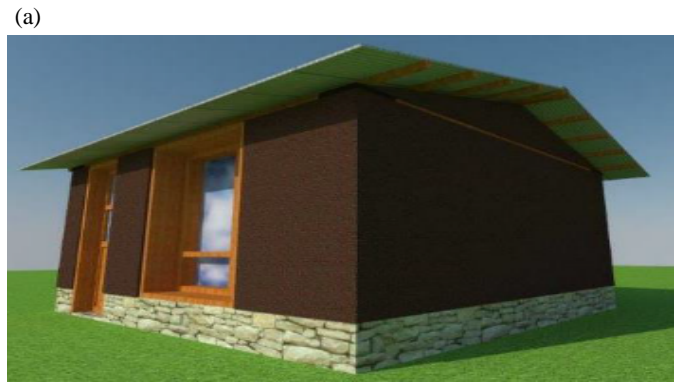

(b)

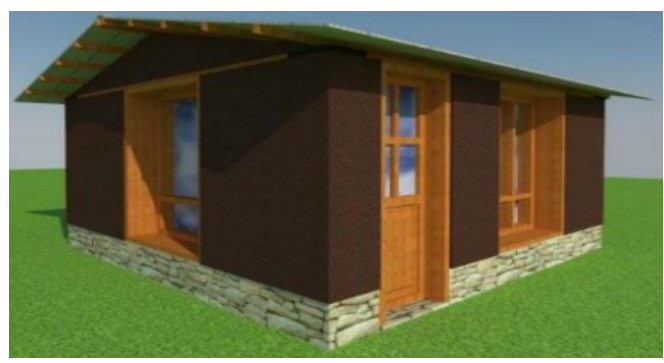

Fig. 8: a) Right side view and b) Left side view

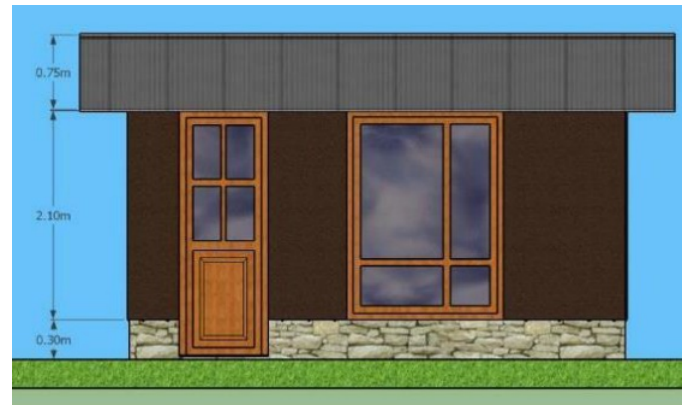

Fig. 9: Front of the house

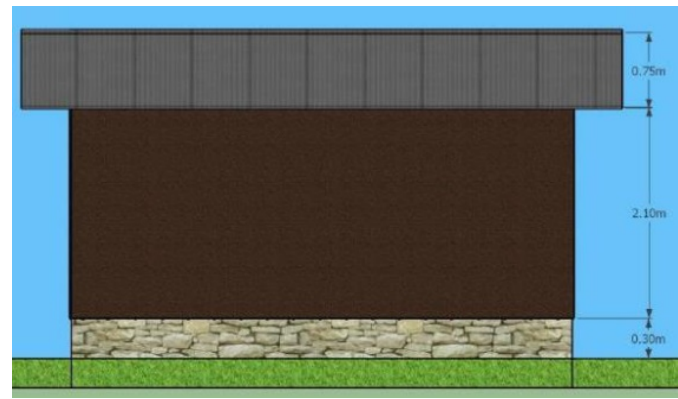

Fig. 10: Back of the house

\section{RESULTS AND DISCUSSION}

Construction system: The foundations are made up of a platform of packed down Earth with concrete blocks along the edges a $5 \mathrm{~cm}$ thick lean concrete surface with chains of cyclopean concrete measuring $60 \mathrm{~cm}$ at the base and $30 \mathrm{~cm}$ high. This type of foundation had to be adapted during construction as a solution to the mud produced by heavy rains. The bales are placed on top of these chains as shown in Fig. 11.

The straw bales overlap by including half a bale every other row. The D12 (12 $\mathrm{mm}$ in diameter) pins were also driven in about every $150 \mathrm{~cm}$.

Figure 12 shows wooden planks that are tightened against the bales using washer and nut in a special working on the $\mathrm{d} 12 \mathrm{~mm}$ pins which as mentioned above are driven in and through-tied to hold the bales in position. This specific working is an original solution providing a certain level of compression and stabilizing forces to the bales.

Figure 13 shows the wooden beams that make up the crowning section of the walls and support the roof's wooden trusses.

Finally, Fig. 14 shows the roof, made of eternit (asbestos-cement sheets) on wooden strips, along with the door and window frames and plastering on the straw walls. The plaster included a first layer with dirt having a 


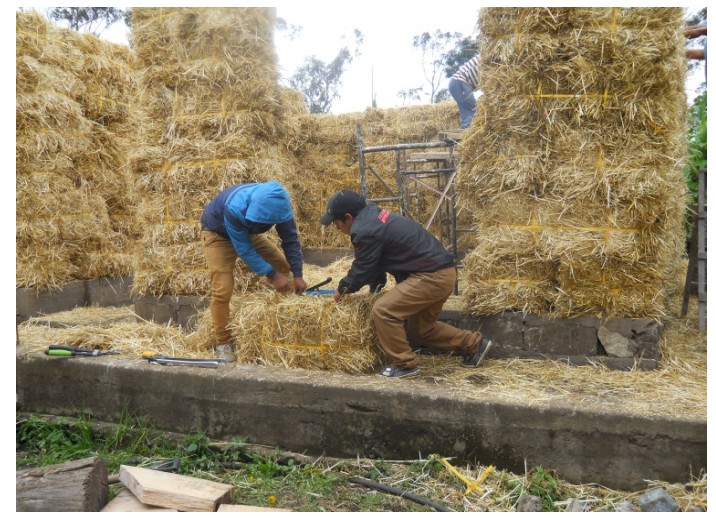

Fig. 11: Foundation and shaping of the structure's straw walls

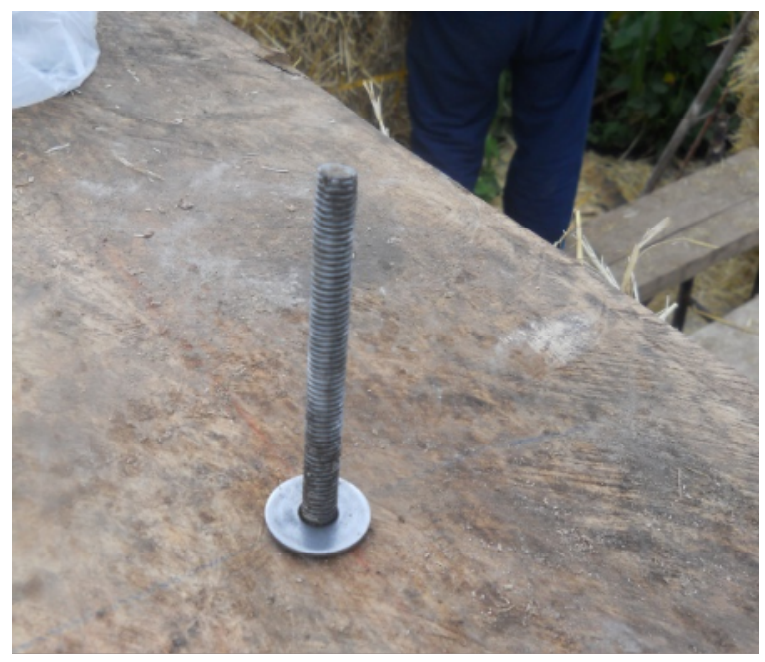

Fig. 12: Detail of the joint between the wooden planks and the bales the screw is missing

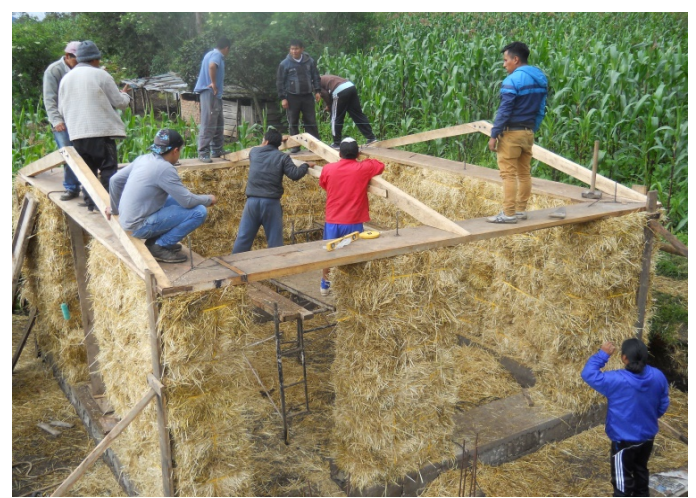

Fig. 13: Perimeter beams and wooden trusses

high content of clay and straw and then a second layer of terrocement in 1:3 proportions. It was laid over hexagonal wire mesh secured to the surface of the straw bales and

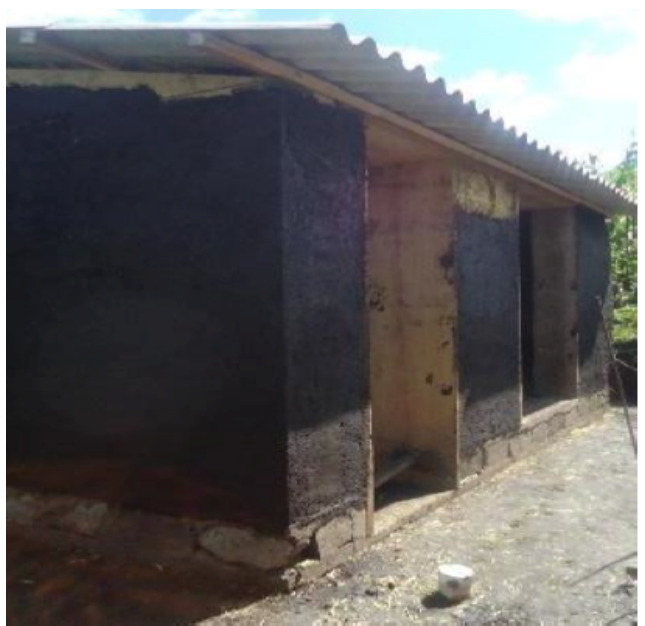

Fig. 14: Home with the plaster applied

Table 3: Characteristics of materials

\begin{tabular}{lcc}
\hline Materials & Young's modulus $(\mathrm{MPa})$ & Density $\left(\mathrm{kN} / \mathrm{m}^{3}\right)$ \\
\hline Strawbale & 1 & 1.0 \\
Wood & 9500 & 9.0 \\
Plaster & 7 & 18.0 \\
Pins & 199948 & 77.0 \\
Concrete & 20000 & 22.0 \\
Asbestos cement & 6800 & 12.4 \\
\hline
\end{tabular}

with a thickness of $4 \mathrm{~cm}$. The characteristics of this plaster coating was also developed by the community during its installation.

It is important to point out that the wall fitting and plastering was performed in a single day, thanks to the generous participation of the Quivillungo Commune residents.

Analytical model: This home was designed using an analytical model. However, this model, much like the construction process was optimized to take into account the observed behavior of the structure upon completion. In following also with the architectural model, a $7 \times 7 \mathrm{~m}$ floorplan was used with wall heights of $2.40 \mathrm{~m}$ and a maximum top height of $3.15 \mathrm{~m}$. The walls were considered to be simply supported.

To determine the Young's modulus of the strawbales (Esb), two tests were made: compression and bending. The information resulting from the compression test was used to calculate a Young's modulus of 2.3 MPa. However, estimation of the same modulus using the bending test resulted in very low values. According to King (2006) Esb is around $1 \mathrm{MPa}$. This is the value that is used in the analytical model, since, it turns out to be an average. The Young's modulus and densities of the different materials are shown in Table 3. 


\begin{tabular}{|c|c|}
\hline Load & Values \\
\hline Permanent (D) & Own weight $+50 \mathrm{kgf} / \mathrm{m}^{2}$ \\
\hline $\begin{array}{l}\text { Temporary (L) } \\
\text { Hail }\end{array}$ & $100 \mathrm{kgf} / \mathrm{m}^{2}$ \\
\hline $\begin{array}{l}\text { Hail } \\
\text { Static equivalent earthquake }\end{array}$ & Vbasal $=\% W r=1.19(\mathrm{D})$ \\
\hline Spectral modal earthquake & $\begin{array}{l}\text { Tfundamental }=0.12 \mathrm{sec}, \mathrm{Sa}=1.19 \mathrm{~g}, 30 \\
\text { Ritz-type vibration modes were used, knot } \\
\text { masses }\end{array}$ \\
\hline
\end{tabular}

The wooden planks used as the wall crowns had a $3 \times 50 \mathrm{~cm}$ section while the trusses measured $8 \times 12 \mathrm{~cm}$. The walls were modeled using finite linear elements. Each component (plaster, strawbales and steel pins) was represented through "layers" with the characteristics of the materials that were used to build them. The bales and plasters were considered shell elements while the pins are taken as membrane elements.

The following loads have been taken into consideration: permanent, temporary, hail, earthquakes on the horizontal $\mathrm{x}$-axis and earthquakes on the perpendicular horizontal $y$-axis. The lateral deformations that were observed in the bales during construction were modeled using the mass-based non-iterative p-delta effect. An equivalent static analysis was performed to calculate seismic loads but the results were compared with those from a spectral modal analysis in accordance with Ecuadorian Construction Standards (NEC 2015). To do so, we took into account soil with regular characteristics (class D) in Bolivar Province. The values we used are shown in Table 4.

Structural analysis results: The compressive $\left(1.3 \mathrm{kN} / \mathrm{m}^{2}\right)$ and shear $\left(1.4 \mathrm{kN} / \mathrm{m}^{2}\right)$ strengths under permanent and temporary loads are relatively low and are easily withstood by the structure.

The first vibration period was parallel to the main facade with a value of $0.12 \mathrm{sec}$. However, 25 additional modes were needed to achieve a $95 \%$ participation of the modal mass. Ritz-type modes were used these were activated by horizontal accelerations parallel to the structure's outer walls. Table 5 compares the periods of the first 5 structural vibration modes as well as the 10,15 , 20 and 25 th modes, providing two options: one taking into account the structural plaster coating and the other without it.

Table 5 shows that the first and second structure vibration periods, finding that the results when taking into account the plaster are lower than those not including plaster.

The largest drift, measured at the top point was 0.0008 with the equivalent static analysis and 0.0005 with the spectral mode. Note that there would be damage in
Table 5: Vibration periods with and without plaster coating

\begin{tabular}{lcc}
\hline Mode & Period with plaster (sec) & Period without plaster (sec) \\
\hline 1 & 0.120 & 0.134 \\
2 & 0.112 & 0.118 \\
3 & 0.099 & 0.073 \\
4 & 0.097 & 0.063 \\
5 & 0.094 & 0.054 \\
10 & 0.073 & 0.026 \\
15 & 0.061 & 0.019 \\
20 & 0.040 & 0.015 \\
25 & 0.024 & 0.009 \\
\hline
\end{tabular}

fragile elements in the event of drift over 0.003 . Compressive strength for seismic loads: $\left(0.9 \mathrm{kN} / \mathrm{m}^{2}\right)$ and shear strength $\left(40 \mathrm{kN} / \mathrm{m}^{2}\right)$ are also relatively low.

\section{CONCLUSION}

Based on results from geographic information systems we identified areas where it would be easier to build single-family homes using strawbales. A series of difficulties had to be overcome; these included building a baler machine. When building the prototype house we applied recommendations from other countrie's standards and tapped into the interest and technical intuition of the Quivillungo community. Finally, based on our observations of the constructed structure we optimized the analytical models.

The research detailed in this study shows that Bolivar and Chimborazo Provinces have relatively large grain crop areas; here, the straw produced is not put to any technical use. The Quivillungo community's interest in participating in the single family strawbale home construction project ended up being a determining factor for carrying it out there. Difficulties which included the lack of baler machines were overcome thanks to the enthusiasm, initiative and technical intuition of the local community. Architectural floorplans and structural calculations used for the single family home served as a guide and confirmed the possibility of building this structure. During construction we followed procedures developed in other countries but adapted them to the reality of Ecuador's Andean Region. For example, the foundations ended up being built on a platform with cyclopean concrete chains to isolate the straw bales from rain and moisture in the environment. Plaster was confirmed as being important in providing rigidity to the bales. This was observed both during construction as well as in the analytical models where without it vibration modes were controlled by the wall flexibility.

Strawbale crowns were another element found to be important in completing the full work on the rigid structure. The ceiling and roof, made up of wooden trusses and covered with asbestos-cement plates was found to be a light element that causes relatively small 
deformations in the straw walls. The stress and deformations caused by permanent, temporary, hail and seismic loads are relatively small. However, the largest stresses are related to shear strength caused by seismic loads. These are mainly absorbed by the plaster. The drifts produced by seismic loads particularly reached values of 0.0008 which are smaller than those that would cause damage to fragile elements which have a value of around 0.003 (NEC 15).

Our conclusion is that the single-family home built in the Quivillungo Community contains several characteristics that facilitate its construction but which also make it possible to ensure that it responds appropriately to daily conditions and exceptional loads (for instance seismic loads) in accordance with national construction standards.

\section{REFERENCES}

Anonymous, 2005. [National housing program project]. Anonymous, 2015. [National Housing Program Project]. Ministerio de Desarrollo Urbano y Vivienda MIDUVI, Ecuador, South America. (In Spainish)

Anonymous, 2018. [Obtained from survey of surface and continuous agricultural production 2016]. Instituto Ecuatoriano de Estadistica y Censos, Quito, Ecuador. (In Spainish) http: //www. ecuadorencifras.gob. ec/estadisticas-agropecuarias-2/
Araneda, L. and A. Munoz, 2010. Analysis of the thermal behavior of the building system with bales of straw. Master Thesis, Universidad del Bio-Bio, Concepción, Chile. (In Spanish)

Bhattarai, P., D.R. Dhakal, K. Neupane and K.S. Chamberlin, 2012. Straw bale in construction of building and its future in India. Intl. J. Modern Eng. Res., 2: 422-426.

Cebada Sanchez, M., 2017. [Build with straw bales: Innovation and popular wisdom (In Spanish)]. Cercha J. Tech. Archit., 132: 74-77.

King, B., 2006. Design of Straw Bale Buildings: The State of the Art. Green Building Media Inc., Toronto, Canada, ISBN:9780976491118, Pages: 260.

Minke, G. and F. Mahlke, 2006. [Manual of Construction with Bales of Straw]. 1st Edn., Fin de Siglo, Montevideo, Uruguay, ISBN: 9974-49-361-7, Pages: 123 (In Spanish).

Nitzkin, R., 2013. [IV Meeting CPR a great success]. Noticias de la Red de Construcción con Paja, Moclinejo, Spain. (In Spanish) https://www. casasdepaja.org/noticias?start $=39$

Nowak, M. and M. Kolaczkowski, 2016. New dimension for straw construction. Czasopismo Techniczne Budownictwo, 112: 107-114.

Pachala Curi, J.L. and H.P. Rosero Munoz, 2016. [Construction system of single-family houses with supporting straw walls]. BA Thesis, Central University of Ecuador, Quito, Ecuador. (In Spanish). 